\title{
Rancang Bangun Kendali Pintu Air Secara Otomatis Dengan Pemberitahuan Informasi Menggunakan SMS Pada Pengairan Persawahan Berbasis Mikrokontroller
}

\author{
Yulastri $^{1}$, Anton ${ }^{2}$,Ilhamdi Taufik ${ }^{3}$ \\ ${ }^{123}$ Jurusan Teknik Elektro Politeknik Negeri Padang \\ yulastri@pnp.ac.id \\ Kampus Politeknik Negeri Padang, Limau Manis Padang
}

\begin{abstract}
Indonesia is commonly known as a tropical country that is rich in biodiversity of flora and fauna which has fertile land and abundant natural products, especially in agriculture. Water is one of the most important elements in agriculture, particularly in rice fields. Normally the water source is coming from lakes, reservoirs, rivers, and from other water sources through waterways to rice fields. These water channels sometimes do not work properly because the sluices that opened manually are not fully open or partly open only so it makes water is not properly channeled to the rice fields. As a result, the farmers' harvest becomes a little, even experiencing crop failure. The automatic sluice control system on the rice field irrigation is a system that will control the paddy irrigation sluice in flowing water according to the conditions of the rice fields. This system uses an ultrasonic sensor to measure the water level in the field. Then the servo motor will move the sluice to open or close according to the readings of the water level from the sensor. Then the SIM800L GSM Module will send an SMS notification that the rice fields are lacking in water and the fields have been filled with water.
\end{abstract}

Keywords: Arduino Uno, HC-SR04 Ultrasonic Sensor, MG996R Servo Motor, LCD, SIM800L Module

\begin{abstract}
Abstrak-Indonesia merupakan negara beriklim tropis yang kaya akan keanekaragaman hayati flora dan fauna dimana memiliki tanah yang subur dan hasil alam melimpah khususnya di bidang pertanian. Air merupakan salah satu unsur terpenting dalam bidang pertanian terutama persawahan. Air tersebut dialiri dari danau, waduk, sungai, dan dari sumber air lainnya melalui saluran-saluran air menuju lahan persawahan. Saluran-saluran air ini kadang kala tak berfungsi dengan baik karena pintu air yang dibuka secara manual tidak terbuka atau setengah terbuka sehingga air tak tersalurkan dengan baik ke lahan persawahan. Akibatnya panen petani menjadi sedikit, bahkan mengalami kegagalan panen. Sistem kendali pintu air secara otomatis pada pengairan persawahan ini adalah sistem yang akan mengendalikan pintu air irigasi persawahan dalam mengalirkan air sesuai kondisi lahan persawahan. Sistem ini menggunakan sensor ultrasonik untuk mengukur level ketinggian air dilahan persawahan. Kemudian motor servo akan mengerakkan pintu air untuk membuka atau menutup sesuai pembacaan jarak permukaan air dari sensor. Kemudian Modul GSM SIM800L akan mengirimkan sms notifikasi bahwa sawah kekurangan air dan sawah telah terisi air.
\end{abstract}

Kata kunci:Arduino Uno, Sensor Ultrasonik HC-SR04, Motor Servo MG 996R, LCD, Modul SIM800L

(C) 2018 Elektron Jurnal Ilmiah

\section{I.PENDAHULUAN}

Perkembangan teknologi dan sains sekarang ini melaju dengan pesat dan luar biasa. Banyak alat-alat yang diciptakan dan dikembangkan oleh orang-orang yang memiliki pemikiran kreatif, membangun, dan inovatif. Hal ini disebabkan oleh kerja keras dan rasa ingin tahu manusia yang sangat besar, sehingga menciptakan sesuatu yang bisa memenuhi kebutuhan kepuasan mereka. Beragam inovasi mereka tawarkan kepada masyarakat dengan berbagai fungsi dan manfaat yang diberikan. Kini dapat dijumpai kecanggihan teknologi yang telah diciptakan hampir di segala bidang.Indonesia merupakan negara beriklim tropis yang kaya akan keanekaragaman hayati flora dan fauna [1] dimana memiliki tanah subur dan hasil alam yang beraneka ragam khususnya di bidang pertanian [2] Sehingga dengan iklim tropisnya, Indonesia hanya memiliki dua musim yaitu musim hujan dan musim kemarau [3]. Ketika musim penghujan, banyak lahan persawahan yang terendam air sehingga membuat para petani gagal panen dan menimbulkan kerugian finansial yang tak sedikit.Karena permasalahan itulah, penulis menemukan sebuah ide atau gagasan pemikiran dengan merealisasikan sebuah alat bantu "Rancang Bangun Kendali Pintu Air Secara Otomatis Dengan Pemberitahuan Informasi Menggunakan Modul GSM SIM800L Pada Pengairan Persawahan Berbasis Mikrokontroler. Tujuan dari pembuatan alat ini yaitu mengontrol pengairan lahan persawahan yang efisien sesuai kebutuhan sehingga kegagalan panen dapat diatasi. Namun demikian, sistim ini bukanlah sistem yang secara baik mengatasi kegagalan panen petani, tetapi akan menjadi tolak ukur untuk mengembangkan inovasi yang lebih baik lagi dalam mengatasi permasalahan ini . 


\section{METODE PENELITIAN}

\section{A.Perancangan Sistem}

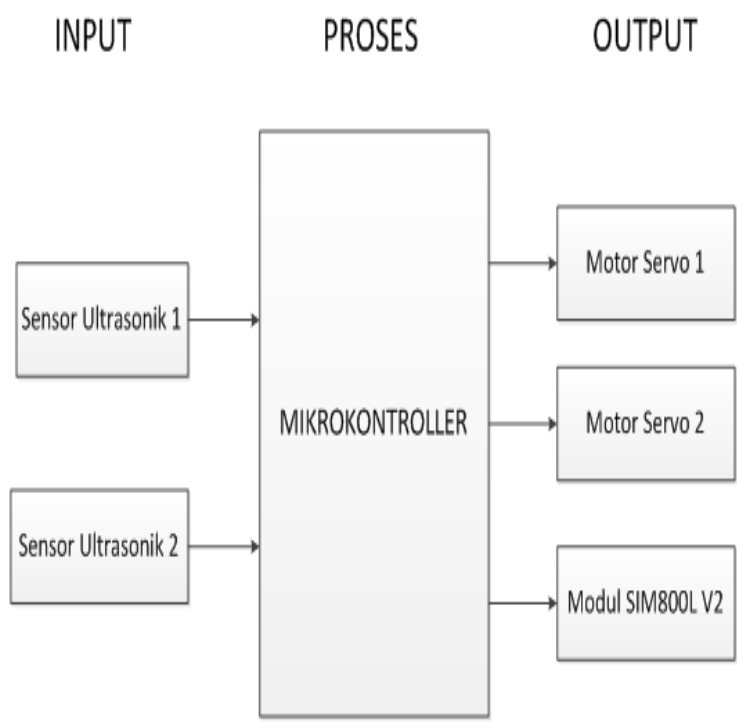

Gambar 1. Blok Diagram

Sistem pengairan otomatis pada lahan persawahan ini merupakan rancang bangun miniatur pengendali air yang masuk dan keluar pada lahan persawahan sesuai kebutuhan tanaman padi serta mengurangi kegagalan panen petani. Kegagalan panen ini muncul diakibatkan curah hujan dan kemarau yang tak menentu sehingga air pada lahan persawahan kadang kala meluap dan berkurang pada lahan pertanian.Sistem ini menggunakan input berupa sensor ultrasonik untuk membaca ketinggian air dan output berupa motor servo untuk membuka atau menutup pintu air irigasi lahan persawahan. Arduino digunakan sebagai mikrokontroller untuk pengendalian atau mengatur pemprosesan data berupa sinyal input dan sinyal output. Adapun blok diagram sistemnya dapat dilihat pada gambar 1 .

Berdasarkan blok diagram diatas, alat ini akan mengendalikan dan memonitoring sistem pengairan pada persawahan sesuai kebutuhan dan kondisinya. Sistem dari alat rancang bangun pengairan otomatis ini akan bekerja dengan memberikan sinyal input hasil pembacaan sensor ultrasonik ke arduino untuk diproses. Setelah data diproses di arduino, data/sinyal tersebut akan dikirim ke motor servo yang kemudian mengerakkan motor untuk membuka atau menutup pintu saluran irigasi yang menuju ke lahan persawahan sesuai hasil pembacaan sensor dan pengolahan data di arduino. Handphone akan menerima notifikasi informasi melalui Modul GSM SIM800L berupa SMS. Untuk menampilkan informasi kerja dari alat, maka digunakan LCD 16x2.

\section{B. Perancangan Hardware}

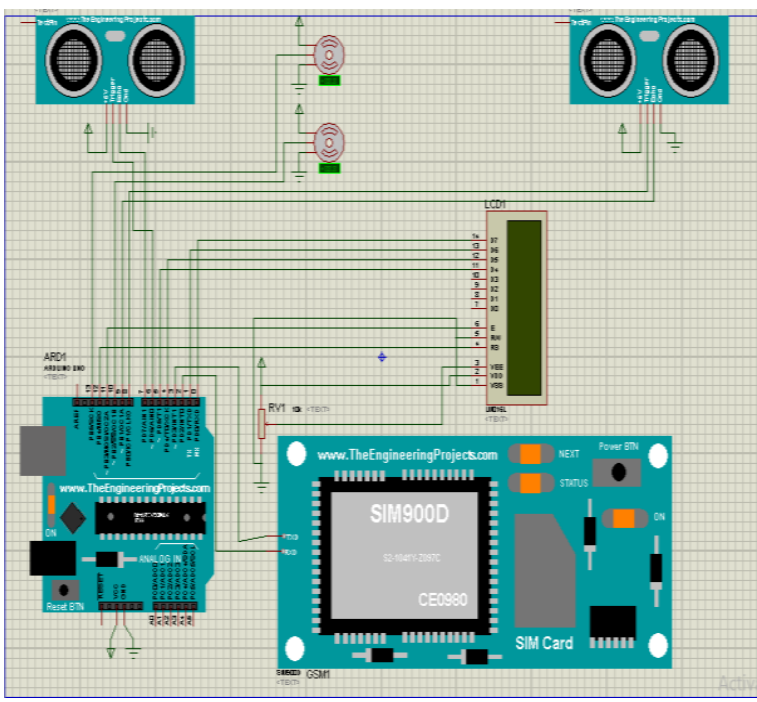

Gambar 2. Schematic Rangkaian Alat

Skematik rangkaian keseluruhan pada Rancang Bangun Kendali Pintu Air Secara Otomatis Dengan Pemberitahuan Informasi Menggunakan Modul GSM SIM800L Pada Pengairan Persawahan Berbasis Mikrokontroller dapat dilihat pada Gambar 2.Sensor yang digunakan pada alat uji 2 buah Sensor Ultrasonik yang berfungsi mengukur ketinggian permukaan air di kedua lahan sawah. Sensor ini memiliki 4 pin yang terhubung ke arduino yaitu Vcc, Echo, Trigger, dan Ground. Pengiriman data sensor ke mikrokontroler dapat dilihat pada tabel 1 .

Tabel 1 pengiriman data dari sensor ke mikrokontroller arduino uno

\begin{tabular}{|c|c|c|}
\hline Sensor & $\begin{array}{c}\text { Jarak } \\
\text { Pembacaan } \\
\text { Sensor }\end{array}$ & Data \\
\hline \multirow{2}{*}{$\begin{array}{c}\text { Sensor } \\
\text { Ultrasonik } \\
1\end{array}$} & Jarak $=15$ & Dikirim \\
\hline & Jarak > 15 & $\begin{array}{c}\text { Tidak } \\
\text { Dikirim }\end{array}$ \\
\hline \multirow{2}{*}{$\begin{array}{c}\text { Sensor } \\
\text { Ultrasonik } \\
2\end{array}$} & Jarak $=15$ & Dikirim \\
\hline & Jarak > 15 & $\begin{array}{c}\text { Tidak } \\
\text { Dikirim }\end{array}$ \\
\hline
\end{tabular}

Motor servo berfungsi sebagai perangkat penggerak yang bekerja berputar secara $\mathrm{CW}$ atau $\mathrm{CCW}$ dengan sudut putaran $0^{\circ}$ dan $360^{\circ}$. Pada alat uji, motor servo yang digunakan berjumlah 2 buah untuk membuka dan menutup 2 buah pintu air irigasi. Motor Servo memiliki 3 pin yang terhubung ke arduino yaitu Vcc, Data, dan Ground.Prinsip kerja motor servo terhadap pintu air dapat dilihat pada tabel 2.

Tabel 2 Prinsip kerja motor servo terhadap pintu air

\begin{tabular}{|c|c|c|c|}
\hline Motor & $\begin{array}{c}\text { Putaran } \\
\text { Motor }\end{array}$ & Pintu 1 & Pintu 2 \\
\hline \multirow{2}{*}{$\begin{array}{c}\text { Motor } \\
\text { Servo } 1\end{array}$} & CCW $180^{\circ}$ & Menutup & - \\
\hline & $\mathrm{CW} 180^{\circ}$ & Membuka & - \\
\hline \multirow{2}{*}{$\begin{array}{l}\text { Motor } \\
\text { Servo } 2\end{array}$} & CCW $180^{\circ}$ & - & Menutup \\
\hline & $\mathrm{CW} 180^{\circ}$ & - & Membuka \\
\hline
\end{tabular}


SIM800L V2 ini terkoneksi ke pin 2 dan 3 Arduino Uno. Pin ini dihubungkan secara cross (bersilangan) dengan pin TX dan RX modul SIM800L V2. Prinsip kerja modul sim8001 v2 terhadap keadaan air sawah dapat dilihat pada tabel 3 .

Tabel 3. Modul SIM800L V2 terhadap keadaan air sawah

\begin{tabular}{|c|c|c|c|}
\hline Sensor & $\begin{array}{c}\text { Jarak } \\
\text { Pembacaan } \\
\text { Sensor }\end{array}$ & $\begin{array}{l}\text { Keadaan } \\
\text { Air } \\
\text { Sawah }\end{array}$ & $\begin{array}{c}\text { SMS yang } \\
\text { dikirimkan Modul } \\
\text { SIM800L V2 }\end{array}$ \\
\hline $\begin{array}{c}\text { Sensor } \\
\text { Ultrasonik } \\
1 \\
\end{array}$ & Jarak > 15 & $\begin{array}{c}\text { Air } \\
\text { Kurang }\end{array}$ & $\begin{array}{c}\text { Sawah } 1 \\
\text { kekurangan air }\end{array}$ \\
\hline $\begin{array}{c}\text { Sensor } \\
\text { Ultrasonik } \\
2 \\
\end{array}$ & Jarak > 15 & $\begin{array}{c}\text { Air } \\
\text { Kurang }\end{array}$ & $\begin{array}{c}\text { Sawah } 2 \\
\text { kekurangan air }\end{array}$ \\
\hline $\begin{array}{c}\text { Sensor } \\
\text { Ultrasonik } \\
1 \text { Dan } \\
\text { Ultrasonik } \\
2 \\
\end{array}$ & Jarak > 15 & $\begin{array}{c}\text { Air } \\
\text { Kurang }\end{array}$ & $\begin{array}{c}\text { Sawah } 1 \text { \& Sawah } \\
2 \text { kekurangan air }\end{array}$ \\
\hline $\begin{array}{c}\text { Sensor } \\
\text { Ultrasonik } \\
1 \text { Dan } \\
\text { Ultrasonik } \\
2\end{array}$ & Jarak $=15$ & $\begin{array}{l}\text { Air } \\
\text { Cukup }\end{array}$ & $\begin{array}{c}\text { Air Di Sawah } 1 \& \\
2 \text { Cukup }\end{array}$ \\
\hline
\end{tabular}

\section{Perancangan Alat Uji}

Perancangan alat uji yang di buat, bentuk dan ukurannya dapat dilihat pada gambar 3 .

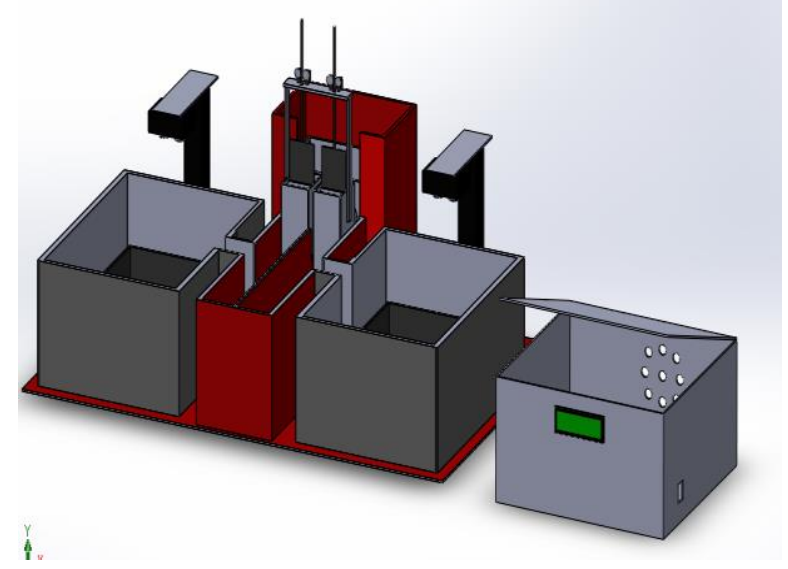

Gambar 3 Perancangan Alat Uji

\section{Perancangan Software}

Perancangan perangkat lunak dimulai setelah perancangan perangkat keras dilakukan. Perangkat lunak yang digunakan ialah bahasa pemograman $\mathrm{C}$ arduino. Untuk mempermudah perancangan perangkat lunak, maka terlebih dahulu dibuat flowchart untuk menggambarkan jalannya program secara keseluruhan terhadap sistem. Dibawah ini merupakan flowchart sistem kendali Pintu Air secara otomatis dengan notifikasi sms pada irigasi persawahan.

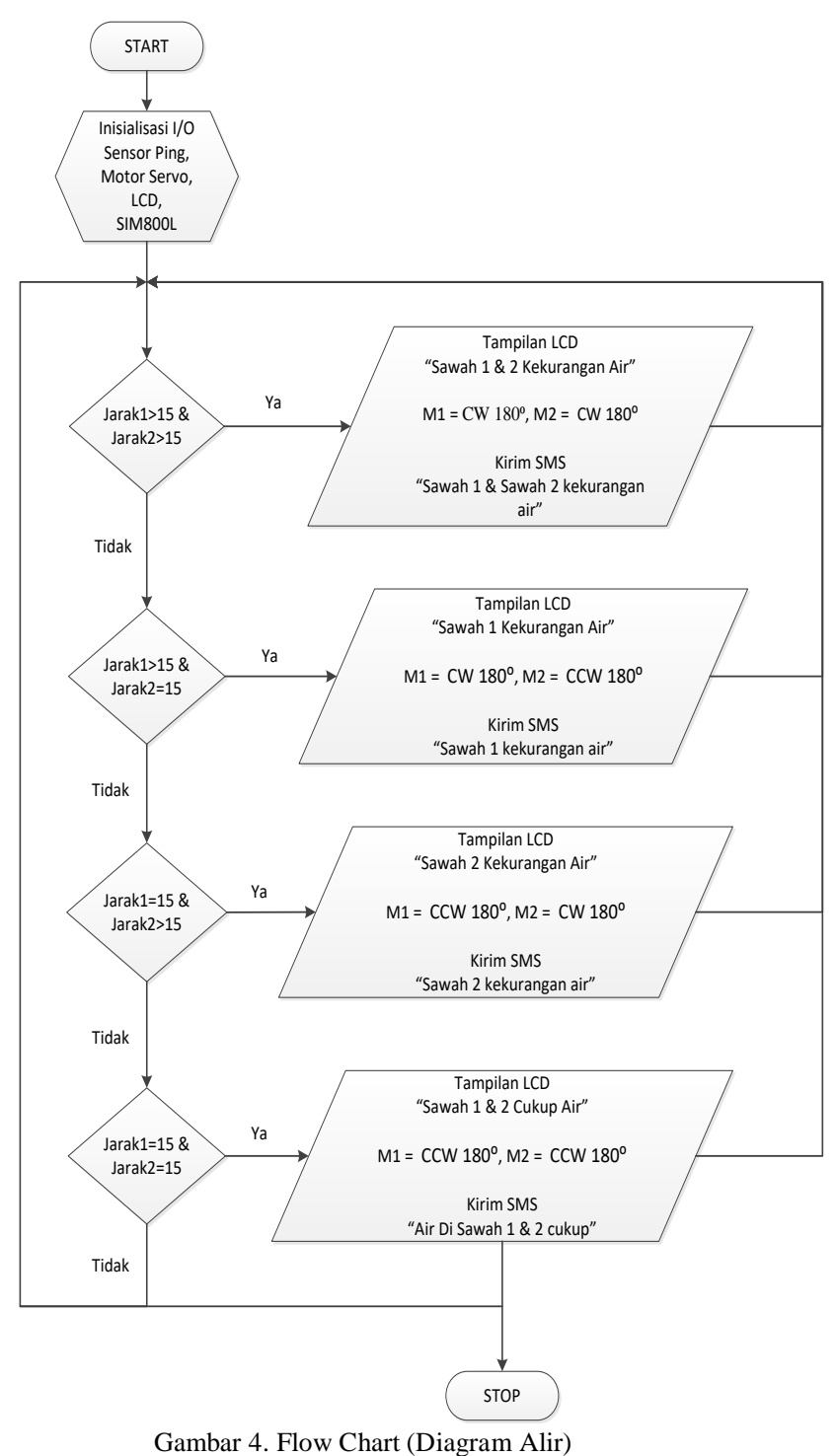

\section{HASIL DAN PEMBAHASAN}

Selanjutnya dilakukan Pengujian dan analisa untuk mengetahui apakah sistem yang dibuat telah sesuai dengan yang direncanakan, Berikut langkah-langkah dan pokok pembahasan yang akan di lakukan dalam pengujian sebagai berikut :

1. Pengujian dan analisa Sensor Ultrasonik HCSR04

2. Pengujian dan analisa Motor Servo MG $996 \mathrm{R}$

3. Pengujian dan analisa SIM800L V2

\section{A. Pengujian dan Analisa Sensor Ultrasonik HC-SR04}

Pengukuran dilakukan pada pin Vcc, pin trigger dan pin echo (pin data sensor) dari sensor ultrasonik. Pengujian yang dilakukan ialah mengukur tegangan dan kemampuan pengukuran sensor ultrasonik terhadap 
benda yang ada didepannya. Hasil pembacaan sensor dapat dilihat pada tabel 4 .

Tabel 4. Data hasil pembacaan sensor ultrasonik HC-SR04

\begin{tabular}{ccc}
\hline $\begin{array}{c}\text { Jarak } \\
\text { Terukur } \\
\begin{array}{c}\text { Mistar } \\
(\mathrm{cm})\end{array}\end{array}$ & $\begin{array}{c}\text { Jarak } \\
\text { Terbaca } \\
\text { Sensor } \\
(\mathrm{cm})\end{array}$ & $\begin{array}{c}\text { Persentase } \\
\text { Kesalahan } \\
(\%)\end{array}$ \\
\hline 3 & 4 & 0 \\
\hline 6 & 6 & 0 \\
\hline 9 & 9 & 0 \\
\hline 12 & 10 & 0 \\
\hline 15 & 15 & 0 \\
\hline
\end{tabular}

Dari hasil pengujian sensor Ultrasonik HC-SR04 pada jarak sebenarnya (Jarak yang diukur manual) dengan jarak yang terbaca oleh sensor, tidak ada selisih jarak yang menandakan bahwa jarak hasil pengukuran sensor sama dengan jarak yang terukur pada mistar, dapat disimpulkan juga persentase kesalahan pengukuran yang didapatkan adalah $0 \mathrm{~cm}$. Hal ini menandakan bahwa sensor ultrasonik bekerja dengan baik. Dari tabel 4 Pengukuran tegangan, didapatkan bahwa daya yang diperlukan oleh sensor untuk dapat bekerja sebesar 4,1 VDC. Sedangkan pada trigger serta echo didapatkan tegangan kerja sebesar 2 VDC dan 0,8 VDC. Jarak $0-15 \mathrm{~cm}$, sensor ultrasonik dapat mengukur jarak tampa adanya perbedaan nilai yang terukur pada mistar dengan nilai yang terukur pada sensor. Perbedaan jarak akan terjadi pada jarak pengukuran $>25 \mathrm{~cm}$ sesuai dengan data sheet sensor ultrasonik HC-SR04. Perbedaan hasil pengujian dengan jarak sesungguhnya dapat disebabkan oleh adanya noise. Modul sensor ultrasonik bekerja seperti gelombang suara yang di keluarkan kelelawar saat terbang atau mencari makanan, dimana sensor mengirim gelombang ultrasonik yang kemudian hasil pantulan gelombang dari benda didepannya ditangkap kembali oleh sensor. Terkadang pantulan gelombang ultrasonik menjadi tidak periodik dan menyebabkan hasil pengukuran gelombang ultrasonik menjadi tidak akurat. Selain itu kesalahan pengukuran juga dapat terjadi karena pembulatan perhitungan pada saat pembuatan program.

\section{B. Pengujian dan Analisa Motor Servo MG $996 R$}

Pengukuran dilakukan pada pin data dan pin ground dari motor servo. Hasil pengukuran dapat dilihat pada tabel 5 .

Tabel 5. Hasil pengukuran pada motor servo

\begin{tabular}{ccc}
\hline $\begin{array}{c}\text { Keadaan Pintu } \\
\text { Air }\end{array}$ & $\begin{array}{c}\text { Besar Sudut } \\
\text { Putaran Motor } \\
\text { Servo }\end{array}$ & $\begin{array}{c}\text { Motor } \\
\end{array}$ \\
\hline Tertutup & $\mathrm{CW} 180^{\circ}$ & $0,5 \mathrm{~V}$ \\
\hline Terbuka & $\mathrm{CCW} 180^{\circ}$ & $0,087 \mathrm{~V}$ \\
\hline
\end{tabular}

Tabel 5, merupakan pengukuran tegangan motor servo pada kondisi putaran dengan sudut $0^{\circ}$ dan $180^{\circ}$. Motor servo akan bergerak apabila sensor ultrasonik mendeteksi kekurangan air, dimana motor akan berputar 180 derajat dan kembali ke posisi 0 derajat setelah air terisi cukup. Pengukuran tegangan dilakukan pada Pin Data dan Pin Ground dimana didapatkan hasil bahwa saat motor servo berputar $\mathrm{CW} 180^{\circ}$ didapatkan tegangan sebesar $0,5 \mathrm{~V}$, sedangkan ketika motor servo berputar CCW $180^{\circ}$ didapatkan tegangan sebesar 0,087 V. Berarti motor servo memerlukan tegangan yang lebih besar untuk berputar dari 0 derajat - 180 derajat.

\section{Pengujian dan Analisa Modul GSM SIM800L}

Pengujian Modul GSM SIM800L V2 dilakukan untuk mengetahui apakah modul ini bisa mengirimkan sms ke nomor handpone pemilik sawah serta mengukur tegangan ketika sms dikirimkan. Pengujian ini dilakukan pada saat pintu air berubah kondisi dari terbuka ke tertutup dan sebaliknya, atau pada saat kondisi sensor ultrasonik membaca ketinggian air pada lahan persawahan.Untuk lahan persawahan yang awalnya kosong atau berisi tetapi tak penuh, maka modul GSM SIM800L V2 akan mengirimkan sms ke pemilik untuk memberikan informasi seperti pada gambar 5, 6 dan 7 .

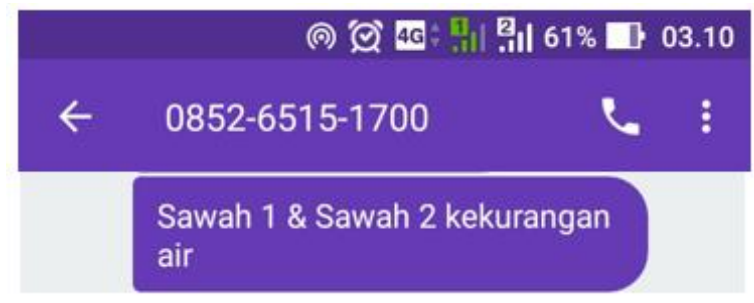

Gambar 5. Penerimaan SMS keadaan sawah $1 \& 2$

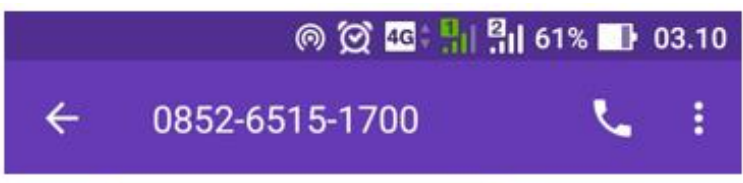

Sawah 1 kekurangan air

Gambar 6. Penerimaan SMS keadaan sawah 1

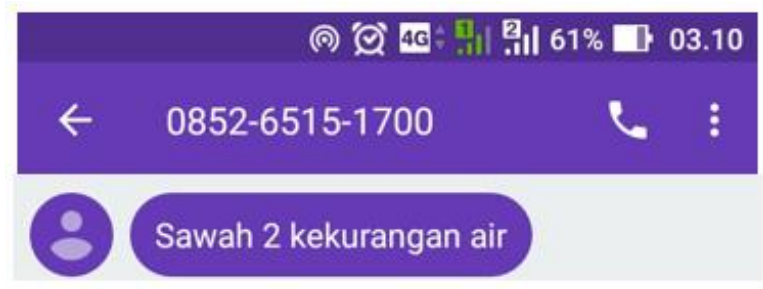

Gambar 7. Penerimaan SMS air tercukupi di sawah $1 \& 2$ 
Pengukuran Tegangan ini dilakukan pada pin $\mathrm{Rx}$ dan Tx modul SIM800L V2. Hasil pengukuran yang didapatkan dapat dilihat pada tabel 6 .

Tabel 6. Pengukuran Tegangan SIM800L V2 saat pengiriman sms

\begin{tabular}{cccc}
\hline $\begin{array}{c}\text { Titik } \\
\text { Pengukuran }\end{array}$ & $\begin{array}{c}\text { PIN } \\
\text { SIM800L } \\
\text { V2 }\end{array}$ & $\begin{array}{c}\text { Tegangan saat } \\
\text { SIM800L V2 } \\
\text { aktif }\end{array}$ & $\begin{array}{c}\text { Tegangan saat } \\
\text { SIM800L V2 } \\
\text { tidak aktif }\end{array}$ \\
\hline TP 1 & RX & $4,96 \mathrm{~V}_{\mathrm{DC}}$ & $1,3 \mathrm{~V}_{\mathrm{DC}}$ \\
\hline TP 2 & TX & $4,96 \mathrm{~V}_{\mathrm{DC}}$ & $1,3 \mathrm{~V}_{\mathrm{DC}}$ \\
\hline
\end{tabular}

Berdasarkan gambar diatas, sms akan di kirim ke handphone menggunakan Modul SIM800L V2 sebagai notifikasi keadaan sawah sebelum dan sesudah pintu air membuka atau menutup sesuai hasil pembacaan ketinggian air oleh sensor ultrasonik. Dari pengujian yang dilakukan dapat dianalisa bahwa untuk mengaktifkan modul SIM800L V2 menggunakan tegangan Vcc / 4,5 - 5,2V_DC. jika tegangan yang diberikan kecil dari 4,5 VDC, maka modul SIM800L V2 tidak akan dapat mengirimkan SMS ke Handphone.

\section{KESIMPULAN}

1. Sensor Ultrasonik bekerja untuk mendeteksi jarak berdasarkan adanya pantulan gelombang ultrasonik, dimana pembacaan ketinggian air sawah dari sensor adalah $>=15 \mathrm{~cm}$.

2. Motor servo akan menggerakan pintu air untuk membuka dengan sudut putaran $\mathrm{CCW}$ 180 derajat dan menutup dengan sudut putaran CW 180 derajat sesuai jarak yang terukur pada sensor ultrasonik.

3. SIM800L V2 adalah modul pengirim SMS notifikasi ke handphone saat sensor ultrasonik HC-SR04 membaca jarak permukaan air lebih dari $15 \mathrm{~cm}$ dan $15 \mathrm{~cm}$ dari sensor.

\section{REFERENSI}

[1] Bhandari V, Abrol P. Field Monitoring of Treated Industrial Waste Water. International Journal of Electrical and Computer Engineering (IJECE). 2013; 3(5): 629-634.

[2] Li L, Cao F, Li Z. Water Level Intelligent System of Data Acquisition and Early Warning. Indonesian Journal of Electrical Engineering and Computer Science. 2014; 12(6): 4671-4678.

[3] Ranjbar MR, Abdalla AH. Development of an Autonomous Remote Access Water Quality Monitoring System. Indonesian Journal of Electrical Engineering and Computer Science. 2017; 8(2): 467-474.

[4] M. Dwisnanto Putro dan Jane Litouw. Robot Pintar Penyambut Costumer pada Pusat Perbelanjaan Kota Manado. Jurnal Rekayasa Elektrika Vol. 13, No. 1, April 2017, hal. 8-17

[5] Ery Safrianti, Rahyul Amri dan Septian Budiman. Prototype Robot Pemadam Api Beroda Menggunakan Teknik Navigasi Wall Follower. Jurnal Rekayasa Elektrika Vol. 10, No. 2, Oktober 2012, hal 83-91

[6] AlFazfri, Jefri. 2017. Rancang Bangun Sistem Pengontrolan Ph Air Pada Condensate Outlet Unit Di PLTU Ombilin Berbasis Mikrokontroller. Padang: Politeknik Negeri Padang

[7] Anton, ST.,MT. "Pengendalian Beban Generator PLTMH Berbasis Mikrokontroller." National Conference of Applied Sciences, Engineering, Business and Information Technology ISSN:2541-111x (2016): https://repo.polinpdg.ac.id//. Web. 19 Jul. 2018

[8] Borror, D.J., Triplehor, N., and Johnson, N.F. 2005. Study of Insect.Ed-7. Amerika: Thomson Brook/ Cole

[9] Malik, Abrar Abdul. 2017. Rancang Bangun Penjemur Pakaian Berbasis Mikrokontroller Menggunakan Modul SIM800L. Padang: Politeknik Negeri Padang

[10] Putra, Desri Aldi. 2017. Sistem Pengaman Brankas Menggunakan RFID Dan Notifikasi SMS Berbasis Mikrokontroller. Padang: Politeknik Negeri Padang

[11] Rahayu, Nofiana Dian., Sasmito, Bandi., Bashit, Nurhadi. "ANALISIS PENGARUH FENOMENA INDIAN OCEAN DIPOLE (IOD) TERHADAP CURAH HUJAN DI PULAU JAWA" Jurnal Geodesi Undip Volume 7, Nomor 1 (2018): https://ejournal3.undip.ac.id//. Web. 19 Jul.2018 